\title{
Energy storage of DFIG based wind farm using D-STATCOM
}

\author{
Kaoutar Rabyi, Hassane Mahmoudi \\ Department of Electrical Engineering, Mohammadia School of Engineers, University Mohammed V, Rabat, Morocco
}

\begin{tabular}{l}
\hline \hline Article Info \\
\hline Article history: \\
Received Dec 29, 2017 \\
Revised Sep 27, 2018 \\
Accepted Oct 25, 2018 \\
\hline Keywords: \\
Active and reactive power \\
DFIG \\
D-STATCOM \\
Supercapacitor \\
Wind farm \\
\hline
\end{tabular}

\begin{abstract}
To accommodate the regularity of wind energy; a storage device is required for the wind turbine. This paper proposesa constant power control for wind farm based Doubly Fed Induction Generator, the suggested storage device is supercapacitor which is connected to every wind turbine of the wind farm, it provides output power stability and compensates the deviations between the available wind energy input and the desired active power output. A Distribution - Static Synchronous Compensator (D-STATCOM) is connected at the point of connection of the wind farm, it controls the active and reactive power according to the demand from orpower generation to the electrical grid. The coordinated approach between the supercapacitors and the D-STATCOM mitigates the voltage magnitude fluctuations of the wind farm and provides support to the active power. Simulation studies are carried out inMATLAB/Simulink.
\end{abstract}

Copyright $@ 2019$ Institute of Advanced Engineering and Science. All rights reserved.

\section{Corresponding Author:}

Kaoutar Rabyi,

Department of Electrical Engineering,

Mohammadia School of Engineers,

University Mohammed V, Rabat, Morocco.

Email: rabyi.kaoutar@gmail.com

\section{INTRODUCTION}

In recent years, renewable energy has gained much attention; it has achieved rapid development and growth. It provides many benefits to the environment, renewable energy is a clean source and has lower impacts on the environments, and lower cost than the conventional energy technologies. For electricity production by wind power, the Doubly Fed Induction Generator (DFIG) is frequently used because of its various advantages; it provides attractive solutions and benefits [1]; the DFIG can operate in wide range of speed variation and generate maximum power [2].

However, like other renewable energy sources, wind energy turns to be unsteady due to the intermittent nature of wind power; the wind speed is influenced by natural and meteorological conditions; the fluctuation of the output power of the wind farm affects frequency, voltage stability, power quality, protection and power dispatching [3]. Wind energy prediction is not always possible; due to the wind speed variation; so, to optimize the performance of the system; power must be supported by reserves, which is more expensive than the electricity market price.

To allow to wind turbines to participate in power regulation, system performance optimization, unit commitment and electricity market movement; energy storage devices are required. Many recent studies have focused on the performance of DFIG wind turbine connected to the Energy Storage System (ESS), this paper proposes a new technique which is connecting the D-STATCOM and the ESS at the same time to the wind farm.The organization of this paper is as follows:

a) Section 2 discusses briefly the different energy storage types for wind power.

b) Section 3 focuses on the DFIG and the supercapacitors as an ESS.

c) Section 4 describes shortly the D-STATCOM as one of the important facts devices.

Finally; in the last section, a comparison between 2 simulations which are carried out in the MATLAB/Simulink; the first simulation consists of a wind farm with a total power of 24MW, each DFIG in 
this wind farm is connected to supercapacitors, the second simulations; the D-STATCOM is connected to this wind farm; the study results show that the system is more stabilized when using the D-STATCOM.

\section{ENERGY STORAGE FOR WIND POWER}

Wind power penetration introduces many technical challenges such as dispatching, control, protection, interconnection to the electrical grid and power quality.

The connection of large wind farm into the grid causesmany problems [4], [5], in particular:

a) Intermittency: the output of a wind farm must be regulated at an acceptable dispatching level; however, it is difficult to balance it; due to the wind speed intermittency, especially in the case of large-scale wind power integration system [6-7].

b) Ramp rate: wind power changes from minute to minute, some ramps exceed the limits, also the sudden die-off and rise restraint the quality of wind power [8], in Figure 1 an example of a daily wind profile, the wind power takes about 13 hours to decrease from the beginning value of $3000 \mathrm{MW}$ to $1100 \mathrm{MW}$ then 4 hours later the wind power becomes $3300 \mathrm{MW}$, the up and down movement creates large peaks, it is difficult to identify the wind power ramping.

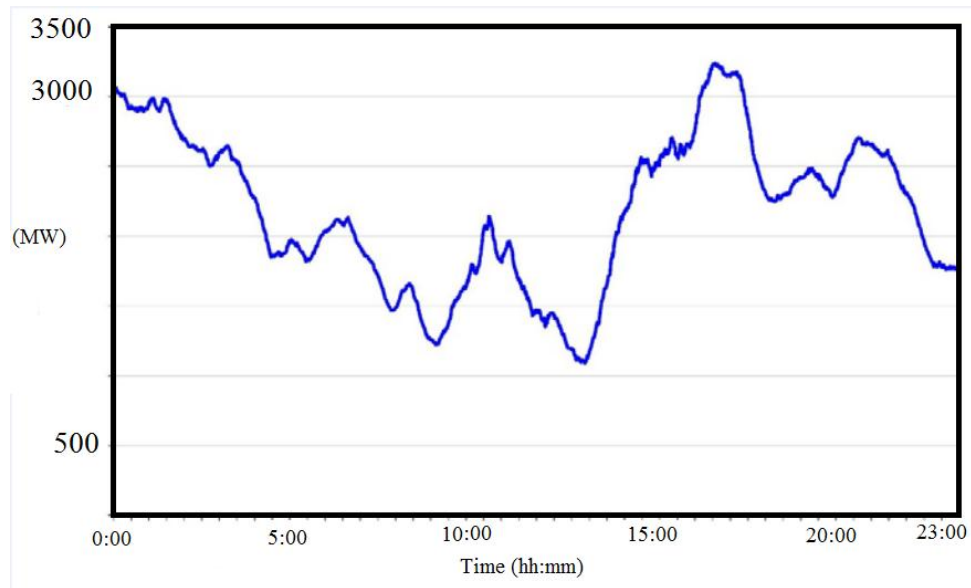

Figure 1. Wind profile example

There are many types of energy storage technologies [9] as it is illustrated in Figure 2:

a) Pumped storagestocksenergy in the form of water in higher reservoir pumped from another lower reservoir. In peaks hours, during the periods of high demand; the stored water is released through turbines like a hydropower station, the released water produces electrical energy [10]

b) Flywheel storage: the main component is a rotor that is accelerated to a high speed, the energy of the system is maintained as a rotational energy which is stored in the flywheel, when dispatching; the flywheel releases the stored energy and the machine works as a generator [10]

c) Compressed air storage: this technique is equivalent to the pumped storage technique, the difference is that the air is compressed under pressure instead of pumped water, when there is an electricity appeal; the compressed air is heated and mixed with natural gas, then expanded in gas turbine for power production [11]

d) Capacitors storage offer rapid charge and discharge cycles, it is composed of two parallel conducting plates separated by a dielectric material [12]

e) Superconducting electromagnets are made from coils of superconducting wire which conduct better than the ordinary wire [13]

f) Thermal storageuses standard cooling equipment, the thermal energy is stocked by heating or cooling a storage medium, then used when there is an energy demand [14] 


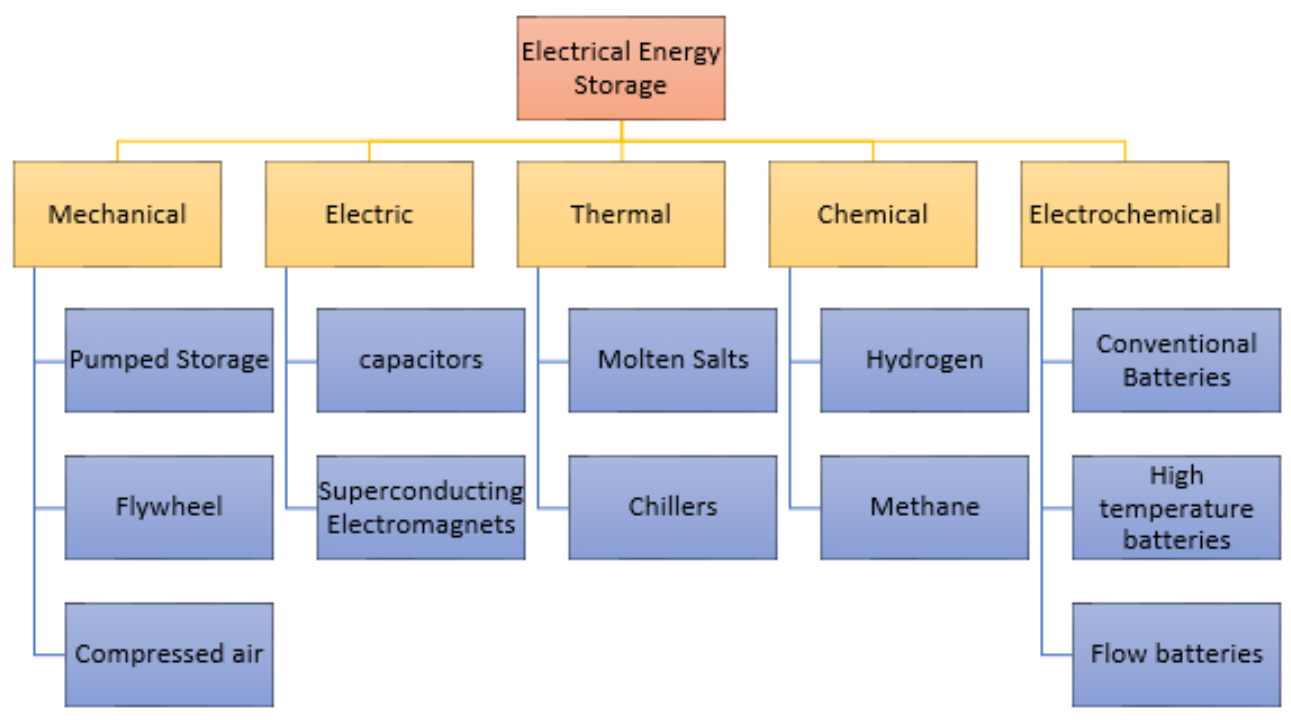

Figure 2. Storage technologies classification scheme

g) The chemical storage: its operation mode is the use of electrolysis water to produce hydrogen in order to stabilize the energy. Hydrogen moleculecould be used as an energy storage, also the use of methane $\left(\mathrm{CH}_{4}\right)$ that results from the conversion of Hydrogen and carbon dioxide [15-16]

h) The conventional battery consists of the use of battery cells, which are connected in different form (series, parallel) to have specific electrical characteristic, cells are compounded of liquid, solid or paste electrolyte with cathode and anode [17]

i) High temperature battery, this type of battery become active at very high temperature $\left(300^{\circ}-340^{\circ}\right)$ by application of heat from external source to dissolve the electrolyte, the heat reduces the turbines performance. But it is very costly [18]

j) The flow battery: its rechargeability is provided by two chemical components dissolved in liquids electrolytes and separated by a membrane, Vanadium Redox (VRB), Polysulphide Bromide (PSB) and Zinc Bromine $(\mathrm{ZnBr})$ batteries are the most typical flow batteries. For the wind power dispatching the $\mathrm{ZnBr}$ battery is used [18]

\section{ENERGY STORAGE FOR DFIG WIND TURBINE}

In this paper the proposed technology of the wind turbine is the DFIG [19-20], the principal of this technology - as shown in Figure 3 is that the rotor windings are connected to the grid via slip rings and a back to back voltage source converter, the active and reactive power can be adjusted from the stator independently of the generator speed.

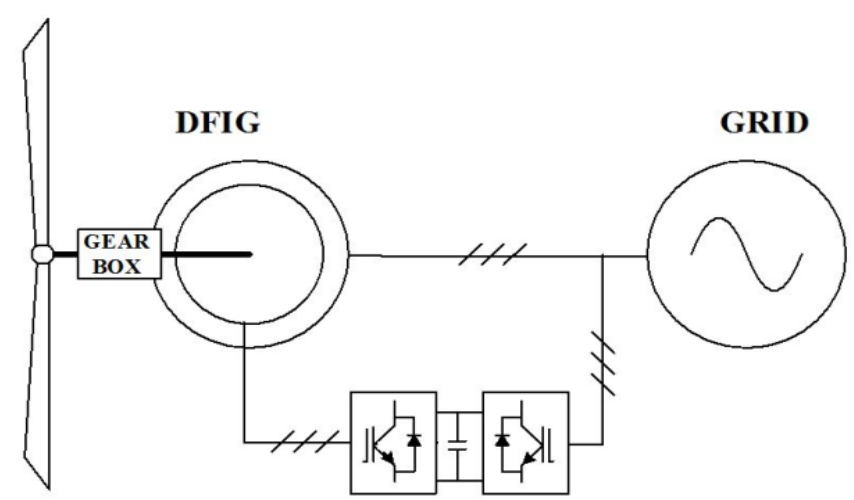

Figure 3. Schematic of DFIG connected to the grid 
The proposed energy storage system (ESS) is the supercapacitor technology, where an electrolyte solution is placed between two solid conductors for the SC, the two quadrants dc/dc converter are connected to the DFIG dc link as shown in Figure 4.

Many researches have been carried out on the use of supercapacitor as an efficient storage technique; the DFIG electrical torque can be regulated due to the improvement of the grid frequency by the supercapacitor [21], [22].

The stored energy is given by Equations (1) and (2),

$$
\begin{aligned}
& E_{E s S}=0.2 P_{\text {nominal }} t \\
& E_{E S S}=\frac{1}{2} C_{\text {ess }}\left(V_{\max }^{2}-V_{\min }^{2}\right)
\end{aligned}
$$

So the capacitance is:

$$
\mathrm{C}_{\mathrm{ess}}=\frac{0.4 P_{\text {nominal }} \mathrm{t}}{\left(V_{\max }^{2}-V_{\min }^{2}\right)}
$$

Where:

- $\quad E_{E S S}:$ the stored energy

- $\quad P_{\text {nominal }}:$ the nominal power

- T: the active circuit time of supercapacitor

- $\quad \mathrm{C}_{\text {ess }}$ : the capacity of the supercapacitor

- $\mathrm{V}_{\max }, \mathrm{V}_{\text {min }}$ : the maximum and the minimum voltage

In this study; the supercapacitors are considered that they have a high energy density with a good efficiency and higher life cycle.

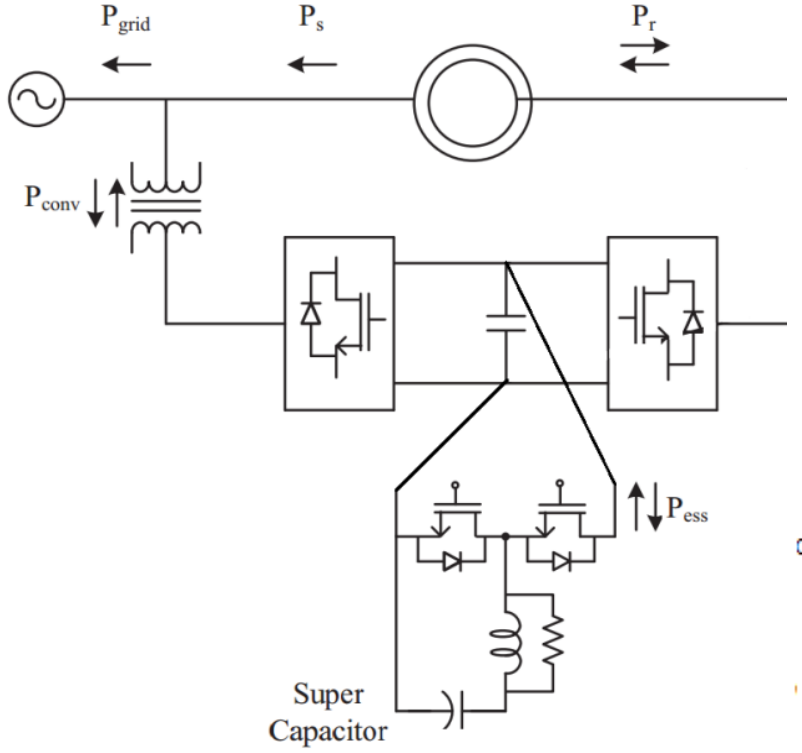

(a)

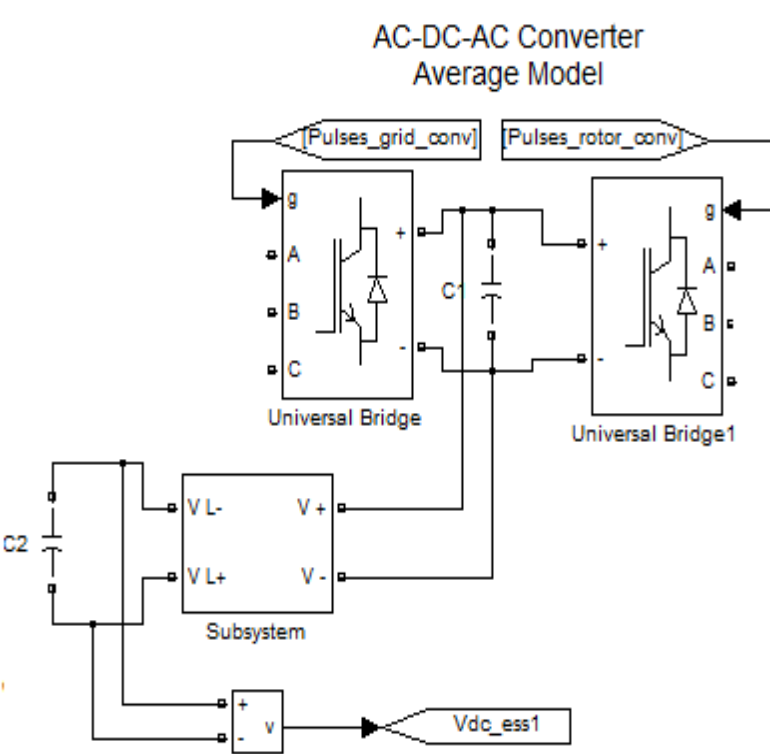

(b)

Figure 4. EESSimulink schema: (a) Schema of the ESS connected to the DC/DC converter, (b) The ESS connected to the DC/DC converter in MATLAB/Simulink

In a wind farm, the reliable process is to connect each wind turbine generator (WTG) with an ESS, and not to connect a large single ESS for the wind farm. When a failure is occurred in the ESS, the other units will not be affected, also the use of ESS reinforce the DFIG dc link [23]. 


\section{D-STATCOM}

The D-STATCOM (Distribution - Static synchronous compensator) (Figure 5) is a one of the important FACTS devices; it consists of power electronics;

a) two-level Voltage Source Converter (VSC).

b) a dc energy storage device.

c) a coupling transformer connected in shunt to the distribution network through a coupling transformer.

The role of a D-STATCOM is to control the power flow and improve transient stability on the distribution network; For more information and description about the D-STATCOM, the reader can consult [24-25].

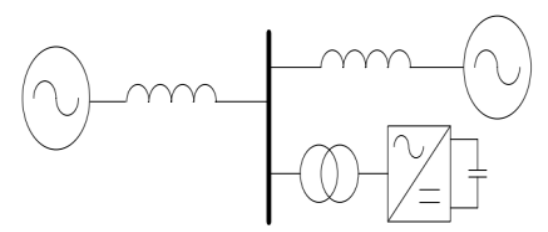

(a)

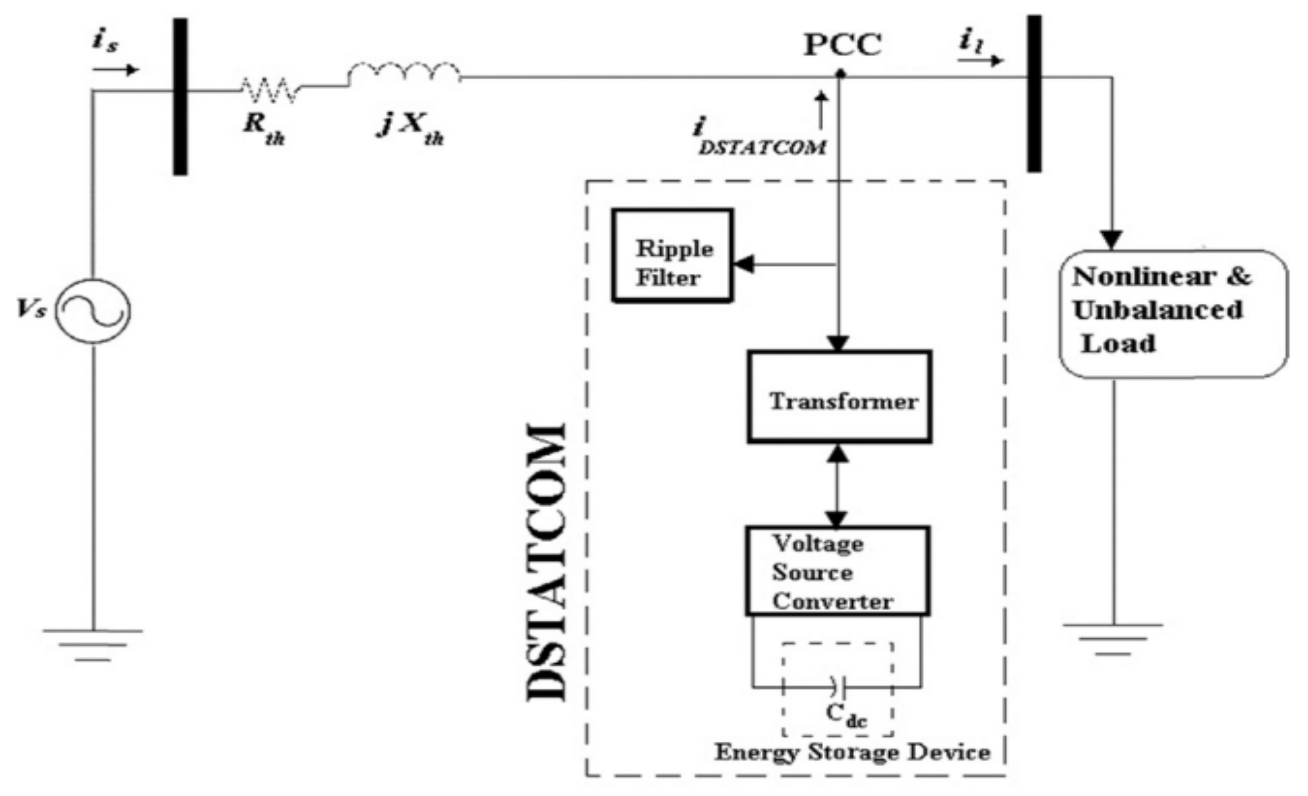

(b)

Figure 5. STATCOM Schema: (a) Transmission line with a STATCOM, (b) Configuration of DSTATCOM in electrical network

The capacitor voltage of the D-STATCOM is given by the equation:

$$
\frac{d V_{D C}}{d t}=\frac{I_{D C}}{C_{D C}}=\frac{m}{C_{D C}}\left(I_{L 0 d} \cos _{\varphi}+I_{L 0 q} \sin _{\varphi}\right)
$$

Where:

- $V_{D C}:$ the DC inverter voltage

- $\quad I_{D C}$ : the inverter current

- $\quad I_{L 0 d}, I_{L 0 q}:$ dq reference values for axes currents

- $\quad C_{D C}$ : the storage capacitor

- $\quad m$ : the pulse width modulation index

- $\varphi$ : the shunt inverter voltage phase angle 
The D-STATCOM must be connected at the middle of the line connecting the grid to the wind farm. The equation expressing the relationship between the network and the D-STATCOM is given by:

$$
I_{B u s}=Y_{B u s} V_{B u s}
$$

Where:

- $I_{B u s}$ : the injected current.

- $\quad Y_{B u s}:$ thenode voltages of the Power System.

- $\quad V_{B u s}$ : the Admittance matrix of the Power System

The D-STATCOM in its basic structure [26] can only exchange reactive power with the network, but if the voltage source inverter is interconnected with an ESS the D-STATCOM can exchange the active power.

\section{WIND FARM SIMULATION}

\subsection{DFIG Connected to the ESS}

The first simulation consists of a wind farm comprising 15 DFIG wind turbine (Figure 6), every DFIG wind turbine has a power of $1.6 \mathrm{MW}$, so a total power of $24 \mathrm{MW}$,

Every DFIG is connected to supercapacitor as it is shown in Figure 4.

The wind farm is connected to the grid via:
a) $25 \mathrm{kV} / 575 \mathrm{~V}$ transformer
b) Electrical line of $35 \mathrm{Km}$
c) Transformer of $120 \mathrm{kV} / 25 \mathrm{KV}$,

The system is connected to a load bus of 2500MVA and $120 \mathrm{KV}$.

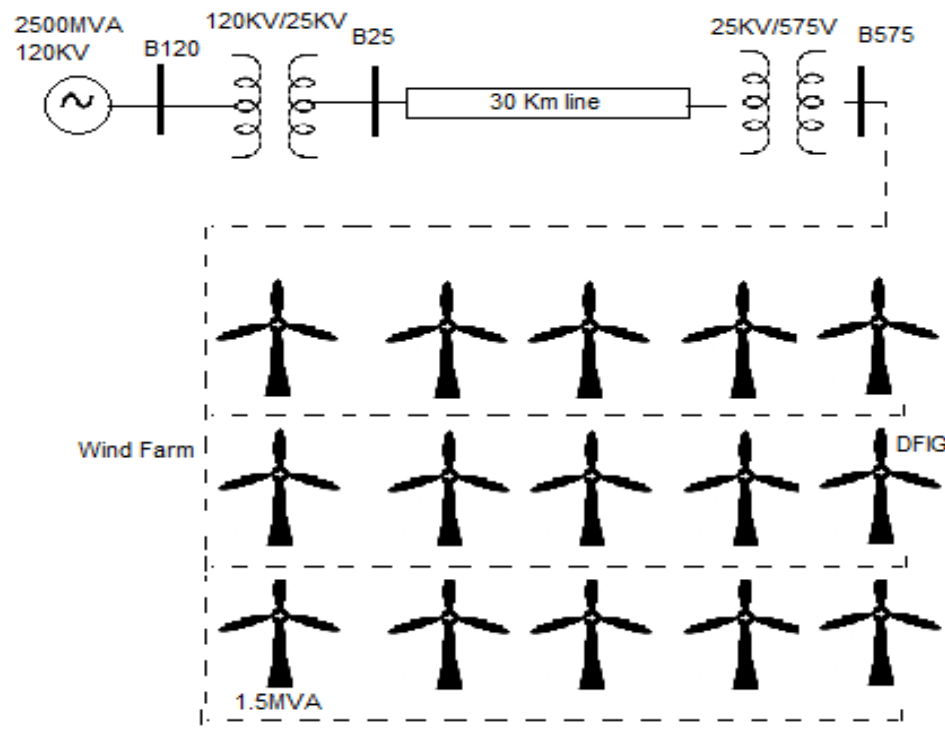

Figure 6. Wind Farm configuration

To generate fluctuations in the electrical quantities; variable wind speed is applied to the wind farm, simulation studies are carried out in the MATLAB/Simulinkenvironment.

Figure 7 shows the voltage of the supercapacitor banks of three chosen wind turbines, these voltages are always maintained constant inside the operating limits [0.5p.u, 1.1p.u], the graphs are constants because the supercapacitors store the energy, even if the wind speed is variable and always maintain the wind turbines voltage balanced.

Figure 8 shows the active $(\mathrm{P})$ and reactive $(\mathrm{Q})$ power measured simultaneously in bus 575 which is the point of connection of the wind turbines, and B 25which is placed before the second transformer $(120 \mathrm{kV} / 25 \mathrm{KV})$. In bus 575; P and Q are maintained constant, however the power demand from or delivery to the electrical grid is not constant as it is shown in Figure 9. Fluctuation began clearly from instant $\mathrm{t}=0.9 \mathrm{~s}$ 

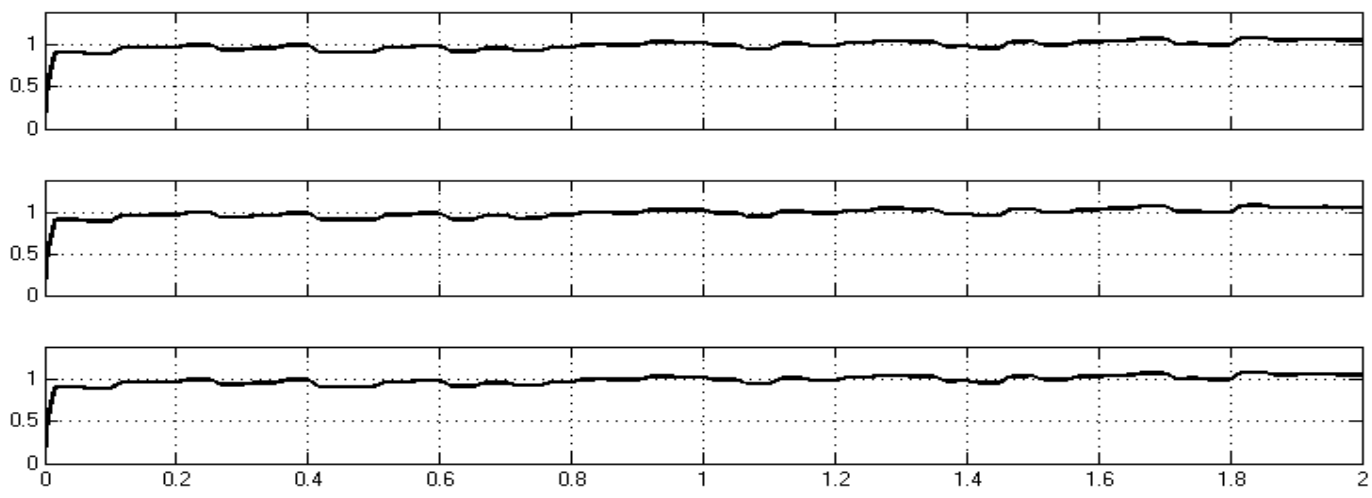

me offset:

Figure 7. voltage of supercapacitor banks of 3 wind turbines

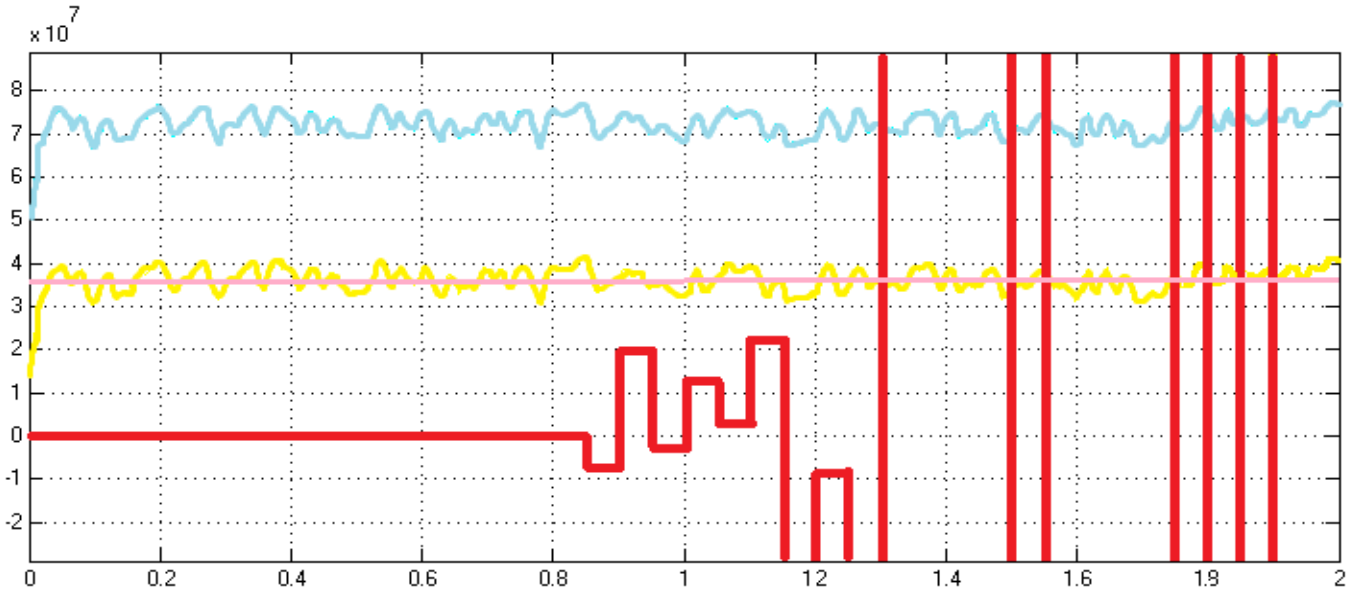

Figure 8. Active and reactive power in B575 and B25

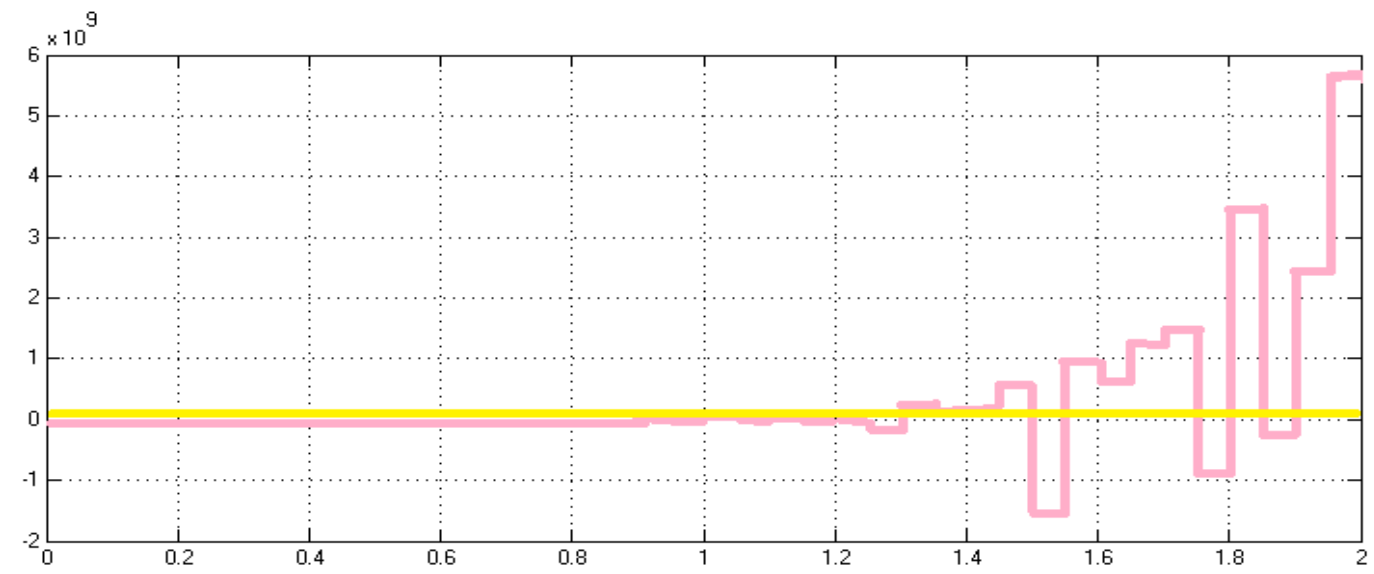

Figure 9. Active and reactive power in Bus 25 (B25) 


\subsection{D-STATCOMconnected to the wind farm (DFIG connected to the ESS)}

The second simulation consists of connecting the D-STATCOM to the previous wind farm as it is shown in Figure 10 the supercapacitors are always connected to the DFIG.

The same characteristics of the wind farm above are used.

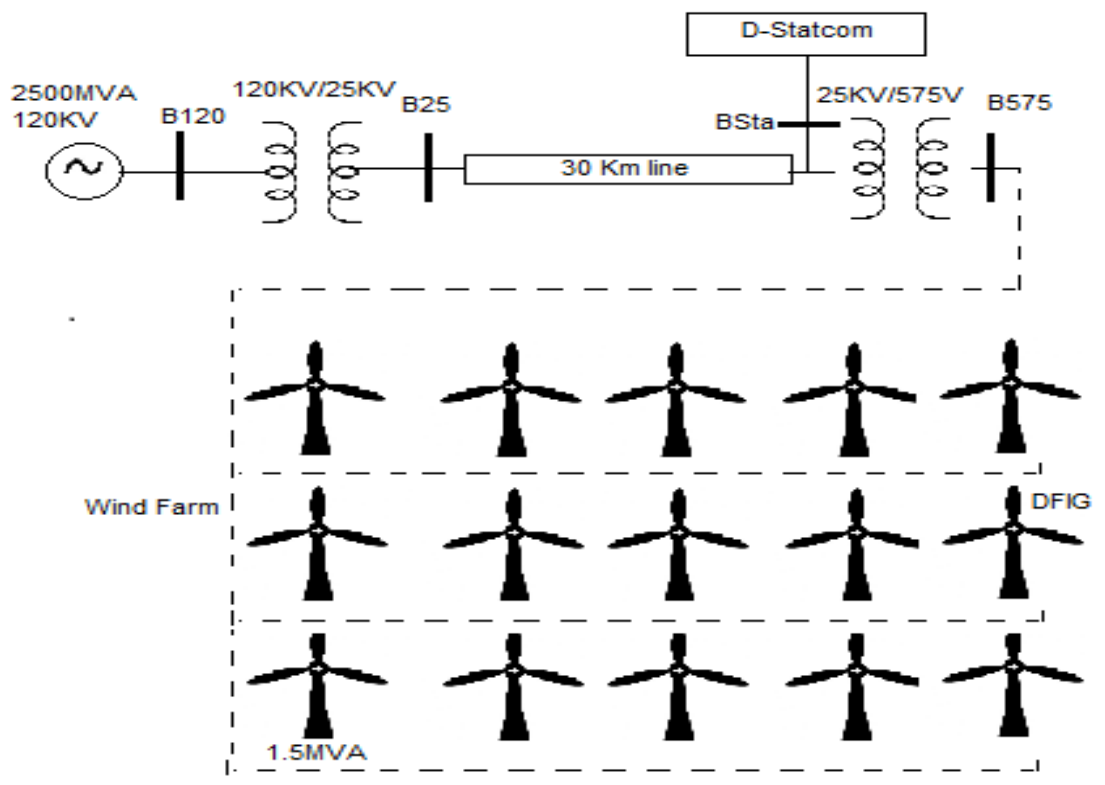

Figure 10. D-STATCOM connected to the wind farm

Figure 11 and Figure 12 show the active $(\mathrm{P})$ and reactive $(\mathrm{Q})$ power measured simultaneously in bus 575 and B 25. In both bus 575 and B25; P \& Q are maintained constant, unlike the last simulation.

The power demand from or delivery to the electrical grid is absorbed then it is maintained constant due to the regulation of the D-STATCOM; unlike the Figure 8 and Figure 9, where disturbance have been noticed at instant $\mathrm{t}=0.9 \mathrm{~s}$.

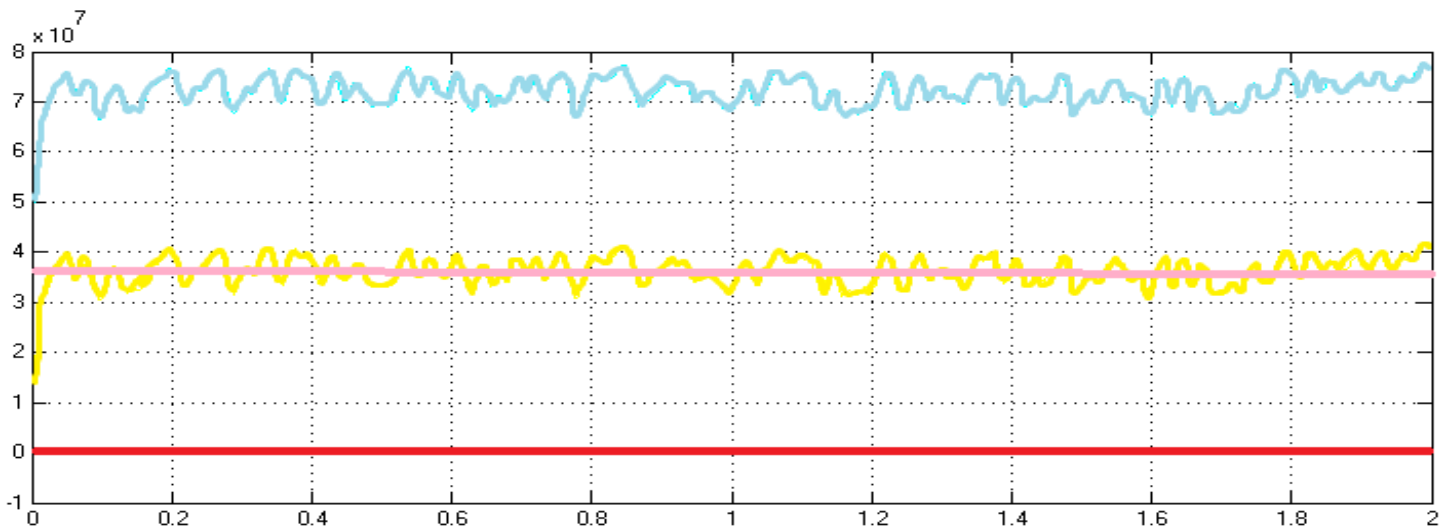

Figure 11. Active and reactive power in B575 and B25

When connecting the D-STATCOM, the real power is improved and the load ability of the power system is enhanced.Integration of the D-STATCOM with the supercapacitors mitigates the voltage magnitude fluctuations and provides support to the active power. 


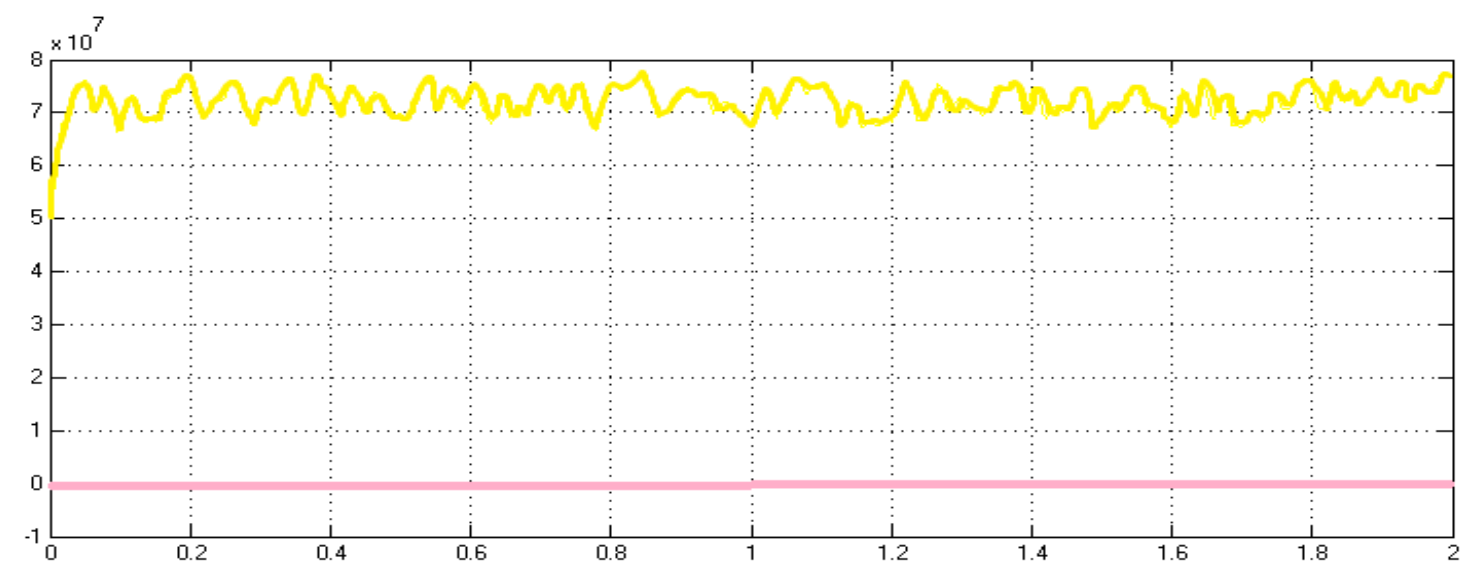

Figure 12. Active and reactive power in B25

\section{CONCLUSION}

This paper proposes coordination between supercapacitor based ESS and D-STATCOM, the ESS is connected to the DFIG while the D-STATCOM is connected in the point of connection of the wind farm based DFIG.

The ESS is connected to the dc link of the DFIG through a two-quadrantdc/dc converter. A simulation of 15 DFIG wind turbines has been carried out in the MATLAB/Simulink.

Results verify the important role of the ESS in maintaining constant the active power, also in ensuring the good dispatching. The use of D-STATCOM has more stabilized the output power of the wind farm, either in power generation or demand from the electrical grid.

\section{APPENDIX}

\begin{tabular}{lc}
\multicolumn{2}{c}{ DFIG and wind turbine parameters } \\
\hline Stator resistance $(\mathrm{pu})$ & 0.05 \\
Rotor resistance $(\mathrm{pu})$ & 0.02 \\
Stator inductance $(\mathrm{pu})$ & 0.1 \\
Rotor inductance $(\mathrm{pu})$ & 0.1 \\
Magnetizing inductance(pu) & 5 \\
Turbine inertia constant (s) & 2.5 \\
Generator inertia constant (s) & 0.5 \\
Shaft compliance constant (pu/rad) & .4 \\
Rated power (MW) & 1.5 \\
\hline
\end{tabular}

\section{REFERENCES}

[1] Zemmit Abderrahim and Messalti Sabir, "Modeling and Simulation of Doubly Fed Induction Motor (DFIM) Control using DTC and DFOC: A Comparative Study," Int J Appl Eng Res, vol. 8, no. 11, pp. 5623-8, 2016.

[2] Naim Cherfia and Djallel Kerdoun, "Wind Energy Conversion Systems Based On a DFIG Controlled By Indirect Vector Using PWM and SVM," International Journal of Electrical and Computer Engineering (IJECE), vol. 6, no. 2, pp. 549-559, April 2016,

[3] S. Teleke, et al., "Control Strategies for Battery Energy Storage for wind farm dispatching," IEEE Trans. Energy Convers., vol. 24, no. 3, pp. 725-732, Sep. 2009.

[4] C. Han, et al., "STATCOM Impact Study on the Integration of a large wind farm into a weak Loop Power System," IEEE Trans. Energy Convers., vol. 23, no. 1, pp. 226-233, Mar. 2008.

[5] Bineeta Mukhopadhyay, et al., "Voltage Compensation in Wind Power System using STATCOM Controlled by Soft Computing Techniques," International Journal of Electrical and Computer Engineering (IJECE), vol. 7, no. 2, pp. 667-680, April 2017.

[6] Guorui Rena, et al., "Measurement and Statistical Analysis of Wind Speed Intermittency," Energy, vol. 118, pp. 632-643, Jan 2017.

[7] T.R. Ayodelen and A.S.O. Ogunjuyigbe, "Mitigation of wind Power Intermittency: Storage Technology Approach," Renewable and Sustainable Energy Reviews, vol. 44, pp. 447-456, 2015 
[8] D. Lee and R. Baldick, "Limiting Ramp Rate of Wind Power Output using a Battery Based on the Variance Gamma Process," International Conference on Renewable Energies and Power Quality (ICREPQ'12) Santiago de Compostela (Spain), 28th to 30th March, 2012.

[9] Luo X, et al., "Overview of Current Development in Electrical Energy Storage Technologies and the Application Potential in Power System Operation," Appl Energy, vol. 137, pp. 511-36, 2015.

[10] R. Sebastián and R. Peña Alzola, "Flywheel Energy Storage Systems: Review and Simulation for an Isolated wind Power System," Renewable and Sustainable Energy Reviews, vol. 16, no. 9, pp. 6803-6813, December 2012.

[11] A. Rogers, et al., "Compressed Air Energy Storage: Thermodynamic and Economic Review," PES General Meeting, Conference \& Exposition, 2014 IEEE.

[12] Nihal Kularatna, "Energy Storage Devices for Electronic Systems Rechargeable Batteries and Supercapacitors, Rechargeable Batteries and Supercapacitors".

[13] Zanming Wang, et al., "Development of Superconducting Magnet for high-field MR Systems in China," Physica C: Superconductivity and its Applications, vol. 482, pp. 80-86, 20 November 2012.

[14] S. M. Hasnain "Review On Sustainable Thermal Energy Storage Technologies, Part I: Heat Storage Materials and Techniques," Energy Convers. Mgmtvol, vol. 39, no. 11, pp. 1127-1138, 1998.

[15] Christensen, et al., "Chemical Energy Storage," DTU International Energy Report 2013.

[16] Erez Wengera, et al., "Thermo-electro-chemical Storage (TECS) of Solar Energy," Applied Energy, vol 190, pp. 788-799, 2017.

[17] J. McDowall, "Conventional Battery Technologies-Present and Future," Power Engineering Society Summer Meeting, 2000, IEEE.

[18] Haoran Zhao, et al., "Review of Energy Storage System for Wind Power Integration Support," Applied Energy, vol. 137, pp. 545-553, 1 January 2015.

[19] Lingling Fan and Zhixin Miao, "Modeling and Analysis of Doubly Fed Induction Generator Wind Energy Systems".

[20] Tarek Medalel Masaud and P. K. Sen, "Modeling and Control of Doubly Fed Induction Generator for Wind Power," North American Power Symposium (NAPS), 2011.

[21] Hao X, et al., "A Hybrid Adaptive Fuzzy Control Strategy forDFIG-based Wind Turbines with Super-capacitor Energy Storage to Realizeshort-term Grid Frequency Support," IEEE in Energy Conversion and Exposition Congress, Montreal, Canada, pp. 1914-8, 2015.

[22] Liyan Qu and Wei Qiao, "Constant Power Control of DFIG Wind TurbinesWith Supercapacitor Energy Storage," IEEE Transactions on Industry Applications, vol. 47, no. 1, January/February 2011.

[23] Chad Abbey, et al., "Supercapacitor Energy Storage forWind Energy Applications," IEEE Transactions On Industry Applications, vol. 43, no. 3, May/June 2007.

[24] Hui Li, et al., "Reactive Power Compensation and DC link Voltage Control using Fuzzy-PIon Grid-connected PV System with d-STATCOM," 2016 IEEE PES Asia-Pacific Power and Energy Conference - Xi'an - China.

[25] Mahela OP and Shaik AG, "A Review of Distribution Static Compensator," Renew Sustain Energy Rev, vol. 50, pp. 531-46, 2015.

[26] CH. Sri Prakash, et al., "A Novel Multi-Functional DSTATCOM with Distribution Generation using FRC Controller," International Journal of Electrical and Computer Engineering (IJECE), vol. 8, no. 3, June 2018, pp. 1373-1382.

\section{BIOGRAPHIES OF AUTHORS}

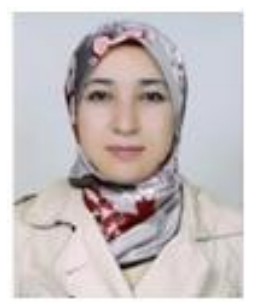

Kaoutar Rabyi was born in Meknès, Morocco, on February 26, 1987. She got her Electrical Engineering degree from National School of Applied Sciences of Oujda in 2010. She is a Ph.d Student in the Electrical Department in Mohammadia School of Engineers, Mohammad 5 University. She is a member of power electronic research department; her research subject is about the integration of wind farms into the electrical grid and the FACTS devices

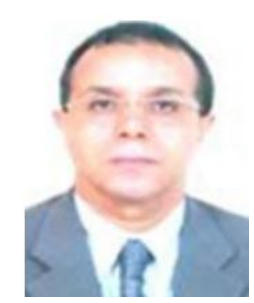

Hassane Mahmoudi Was born in Meknes, Morocco, on January 4, 1959. He received B.S degree in electrical engineering from Mohammadia School of Engineers, Rabat, Morocco, in 1982, and the Ph.D degree in power electronic from Montefiore Institute of Electrical Engineering, Luik, Belgium, in 1990. He was an assistant professor of physics, at the Faculty of Sciences, Meknes, Morocco, from 1982 to 1990. Since 1992, he has been a professor at the Mohammadia Schools of Engineers, Rabat, Morocco, and he was the head of electric engineering department during four years (1999, 2000, 2006 and 2007). His research interests include static converters, electrical motor drives, active power filters and the compatibility electromagnetic. 